\title{
Diversification of myco-heterotrophic angiosperms: Evidence from
} Burmanniaceae

\author{
Vincent Merckx*1, Lars W Chatrou ${ }^{2}$, Benny Lemaire ${ }^{1}$, Moses N Sainge ${ }^{3}$, \\ Suzy Huysmans ${ }^{1}$ and Erik F Smets ${ }^{1,4}$
}

\begin{abstract}
Address: ${ }^{1}$ Laboratory of Plant Systematics, K.U. Leuven, Kasteelpark Arenberg 31, P.O. Box 2437, BE-3001 Leuven, Belgium, ${ }^{2}$ National Herbarium of the Netherlands, Wageningen University Branch, Generaal Foulkesweg 37, NL-6703 BL Wageningen, The Netherlands, ${ }^{3}$ Centre for Tropical Forest Sciences (CTFS), University of Buea, Department of Plant \& Animal Sciences, P.O. Box 63, Buea, Cameroon and ${ }^{4}$ National Herbarium of the Netherlands, Leiden University Branch, P.O. Box 9514, NL-2300 RA, Leiden, The Netherlands
\end{abstract}

Email: Vincent Merckx* - vincent.merckx@bio.kuleuven.be; Lars W Chatrou - lars.chatrou@wur.nl; Benny Lemaire - benny.lemaire@bio.kuleuven.be; Moses N Sainge - sainge2001@yahoo.com; Suzy Huysmans - suzy.huysmans@bio.kuleuven.be; Erik F Smets - erik.smets@bio.kuleuven.be

* Corresponding author

Published: 23 June 2008

BMC Evolutionary Biology 2008, 8:178 doi:10.1 I86/147|-2/48-8-178
Received: 25 February 2008

Accepted: 23 June 2008

This article is available from: http://www.biomedcentral.com/I47I-2I 48/8/I78

(c) 2008 Merckx et al; licensee BioMed Central Ltd.

This is an Open Access article distributed under the terms of the Creative Commons Attribution License (http://creativecommons.org/licenses/by/2.0), which permits unrestricted use, distribution, and reproduction in any medium, provided the original work is properly cited.

\begin{abstract}
Background: Myco-heterotrophy evolved independently several times during angiosperm evolution. Although many species of myco-heterotrophic plants are highly endemic and longdistance dispersal seems unlikely, some genera are widely dispersed and have pantropical distributions, often with large disjunctions. Traditionally this has been interpreted as evidence for an old age of these taxa. However, due to their scarcity and highly reduced plastid genomes our understanding about the evolutionary histories of the angiosperm myco-heterotrophic groups is poor.

Results: We provide a hypothesis for the diversification of the myco-heterotrophic family Burmanniaceae. Phylogenetic inference, combined with biogeographical analyses, molecular divergence time estimates, and diversification analyses suggest that Burmanniaceae originated in West Gondwana and started to diversify during the Late Cretaceous. Diversification and migration of the species-rich pantropical genera Burmannia and Gymnosiphon display congruent patterns. Diversification began during the Eocene, when global temperatures peaked and tropical forests occurred at low latitudes. Simultaneous migration from the New to the Old World in Burmannia and Gymnosiphon occurred via boreotropical migration routes. Subsequent Oligocene cooling and breakup of boreotropical flora ended New-Old World migration and caused a gradual decrease in diversification rate in Burmanniaceae.
\end{abstract}

Conclusion: Our results indicate that extant diversity and pantropical distribution of mycoheterotrophic Burmanniaceae is the result of diversification and boreotropical migration during the Eocene when tropical rain forest expanded dramatically. 


\section{Background}

Myco-heterotrophic plants present a number of unique challenges to those who are trying to understand their diversification and distribution. Many myco-heterotrophic plant species are rare and have very limited distribution ranges [1-4]. Their tiny, dust-like, seeds are assumed to be dispersed by wind or rainsplash [5]. This strategy seems ineffective for long-distance dispersal particularly because most species grow on the forest floor of dense primary rain forests. Furthermore their occurrence seems limited by their interaction with specific arbuscular mycorrhizal fungi, from which they obtain their organic carbon $[6,7]$. Paradoxally, some myco-heterotrophic genera are widely distributed often with remarkable disjunctions. Examples are Sciaphila (Triuridaceae), Burmannia and Gymnosiphon (Burmanniaceae), Thismia (Thismiaceae), Voyria (Gentianaceae) and Monotropa (Ericaceae), which all occur both in the New and the Old World [5]. While the disjunct distribution of Voyria has been interpreted as a result of a long-distance dispersal event [8], the widespread distributions of Sciaphila, Burmannia, Gymnosiphon, and Thismia were traditionally explained as an indication for a great antiquity, allowing vicariance explanation of the observed patterns $[5,9,10]$. This would imply that these genera originated before the breakup of western Gondwana, about 90-105 million years ago (Mya) [11,12]. A recent molecular dating analysis on monocots would not refute the western Gondwana vicariance hypothesis for Burmanniaceae (including Thismiaceae), as the stem and crown nodes of the family were estimated at 116 and 93 Mya respectively [13]. These dates would roughly put the relevant divergences in a Late Cretaceous timeframe, in particular when considering the generally large confidence intervals associated with molecular dating experiments in flowering plants [14]. The results of Janssen and Bremer [13], however, were based on 14 species of Dioscoreales, only three of which belong to the Burmanniaceae. Poor taxon sampling is one of the sources of error in molecular dating, though the effect of undersampling may depend on the method used to accommodate for rate variation [14-16].

The fossils used to calibrate the tree are another possible source of error in molecular dating [17]. Ambiguously interpretable morphology may result in the calibration of an erroneous node, and uncertain age of fossil-bearing rock may give rise to inaccurate dates $[17,18]$. Burmanniaceae are absent from the fossil record. A common approach in similar cases is to apply secondary calibration, i.e. use ages derived from other molecular dating estimates. This approach has been criticized for generating large confidence intervals [19]. We choose to rigorously expand our taxon sampling, including all monocot lineages, to estimate branch lengths based on one of the most widely available markers (18S rDNA), and to constrain the phylogeny to the most accurate phylogenetic hypotheses available in the literature. The date estimates of this single gene approach are compared with a Bayesian relaxed clock phylogenetic analysis [20] that uses secondary calibrations on a multi-gene Burmanniaceae dataset.

In this study we attempt to elucidate the diversification and biogeographic history of one of the most species-rich clades of myco-heterotrophic plants, the Burmanniaceae, by analyzing a thoroughly sampled data set containing nuclear and mitochondrial sequence data. The family consists of seven species-poor Neotropical genera and two species-rich genera with a pantropical distribution (Burmannia and Gymnosiphon). While the pantropical distributions of many angiosperm groups were traditionally interpreted as a result of tectonic vicariance, recent molecular dating studies have lead to a revival of long-distance dispersal theories [21,22]. Most recent studies on disjunct dispersal patterns between the Old and the New World of angiosperm families have strongly rejected vicariance as an explanation for the observed biogeographic pattern (e.g. Malpighiaceae [23], Rapateaceae and Bromeliaceae [24], Sapotaceae [25], Burseraceae [26], Melastomataceae [27], Moraceae 28], Meliaceae [18], Renealmia [29].

\section{Results \\ Phylogenetic analyses}

The three data partitions comprised the following numbers of taxa and characters: (1) $18 \mathrm{~S}$ rDNA with 51 accessions, 1694 characters, and 222 parsimony-informative characters; (2) nad1 b-c intron with 49 accessions, 1645 characters, and 275 parsimony-informative characters plus Simple Indel Coding of the gaps adding 112 parsimony-informative characters; (3) ITS with 47 accessions, 598 characters, and 372 parsimony-informative characters.

One of the six most parsimonious trees (tree length 4215; CI 0.522; RI 0.687) recovered during the parsimony analysis on the combined data is shown in Figure 1. No significant difference was observed between the maximum parsimony strict consensus tree and the Bayesian 50\% majority-rule consensus tree. Most clades are well-supported ( $\geq 85 \%$ bootstrap support $/ \geq 95 \%$ Bayesian posterior probability). A well-supported clade with two samples of Burmannia congesta and Campylosiphon is sister to all other Burmanniaceae. Consequently, Burmannia is a paraphyletic genus. The neotropical genus Dictyostega is sister to the rest of the ingroup. Apteria is sister to the core Burmannia clade. Within the core Burmannia species $B$. sphagnoides is sister to the other species, consisting of two neotropical, two African, one Madagascan, and three East Asian clades. Hexapterella is sister to Gymnosiphon. Cymbocarpa is embedded in the Gymnosiphon clade. This clade 


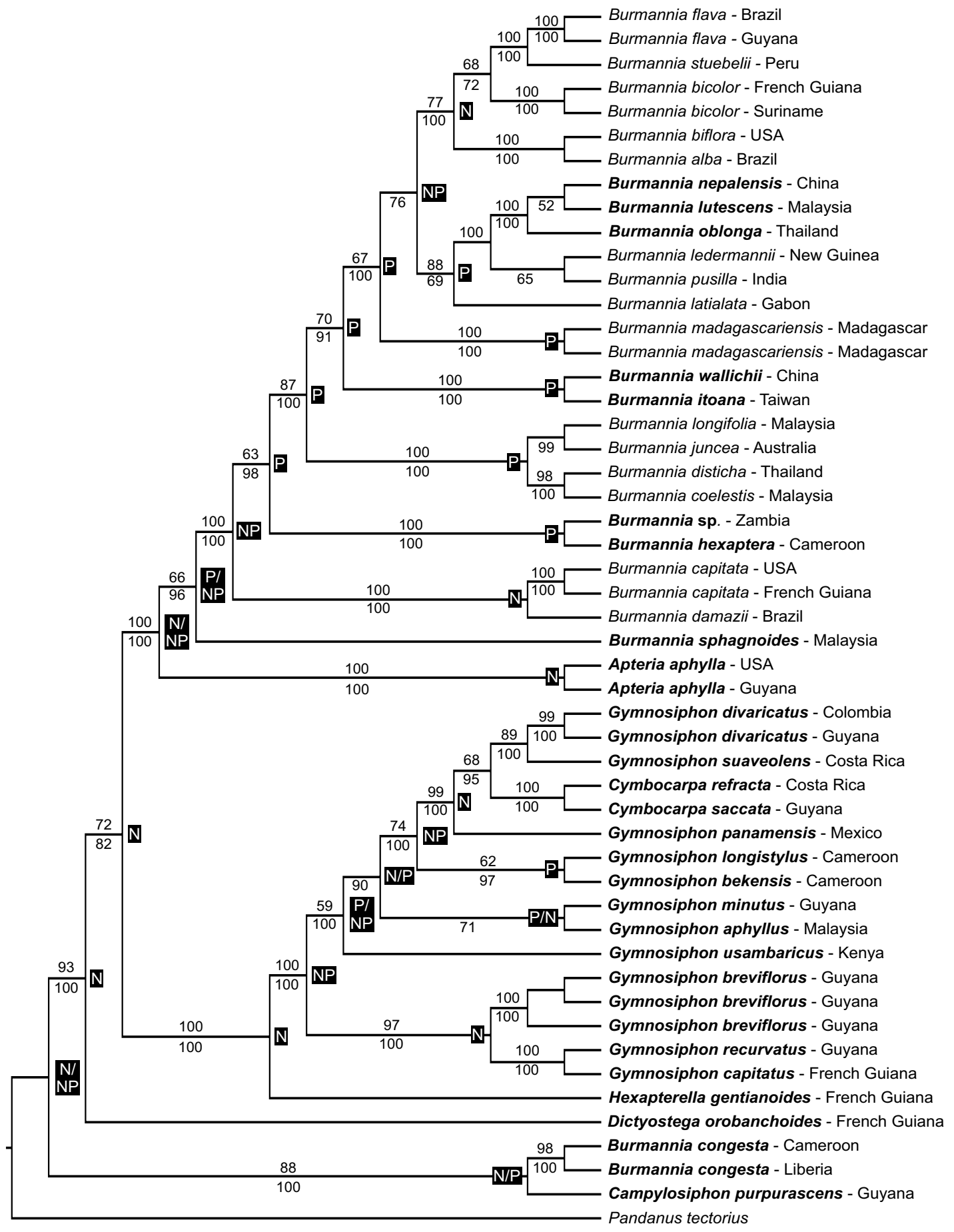

Figure I

Phylogenetic relationships of Burmanniaceae based on phylogenetic analysis of the 3-gene dataset. One of the six most parsimonious trees for the combined I8S rDNA, ITS, and nad I b-c data. Numbers above branches are bootstrap percentages from the maximum parsimony analysis. The Bayesian posterior probabilities are shown below branches. Black boxes show ancestral area reconstructions with DIVA. $\mathrm{P}$ and $\mathrm{N}$ indicate paleotropics and neotropics respectively. A slash separates two equally likely ancestral area hypotheses. Achlorophyllous species are shown in bold. 
consists of three neotropical, one East Asian, and two African lineages.

\section{Molecular dating}

The 50\% majority-rule consensus tree of the constrained Bayesian analysis of the $18 \mathrm{~S}$ rDNA monocot dataset with optimized branch lengths is shown in Figure 2. The age estimations with their standard deviations and credibility intervals obtained for the monocot orders Acorales, Alismatales, Petrosaviales, Dioscoreales, Pandanales, Liliales, Asparagales, Arecales, Zingiberales, Commelinales, and Poales are listed in Table 1. The stem-node age of the Burmanniaceae is estimated to $116 \pm 2.6 \mathrm{Mya}$, the crown node to $96 \pm 3.37$ Mya. The Burmanniaceae clade clipped from the r8s chronogram of the monocots is shown in Figure 3. The crown and stem age estimates of the Burmanniaceae were used as secondary calibration points for the multigene analysis with BEAST. The chronogram resulting from this analysis is also shown in Figure 3.

\section{Tempo of diversification}

We measured a negative $\gamma$ value for our chronogram $(\gamma=-$ 6.51), which rejects the hypothesis that rates of lineage accumulation in Burmanniaceae remained constant over time, in favour of a decrease of speciation rate through time [30]. Simulations indicate that with a sample of 41 species for the $\gamma$-statistic to yield -6.51 when the true value is zero, there would need to be 562 species of Burmanniaceae (95\% CI: 139-1708) (Figure 4). We can therefore reject the possibility that the negative $\gamma$-value is the result of a poor sampling artefact.

\section{Lineage-through-time plot}

A semilogarithmic lineage-through-time (LTT) plot (Figure 5) shows a trend toward reduced diversification rates beginning $\approx 72$ Mya (Late Cretaceous), and an Eocene increase of diversification rate. A model of gradual change in diversification rate (model $\mathrm{B}, \gamma=1.65, \mathrm{AIC}=360.15$ ) was chosen over model A (AIC $=371.05)$ and model C $(\mathrm{AIC}=391.02)$ as best fit of the empirical LTT plot using AIC. Model B was preferred no matter which timing of an abrupt rate shift in model $\mathrm{C}$ was specified. The hLRT showed significant difference between model A and B (P $=0.0004)$, while there was no significant difference between model A and C.

Significant diversification rate shifts were detected in two branches by the $\Delta 1, \Delta 2$, and the Slowinski and Guyer (SG) statistic (Figure 5, branches 1 and 2). The relative cladogenesis (RC) test identified four different branches with rate shifts (Figure 5, branches 3-6). The shifts identified by RC should be treated with caution as the RC test is sensitive to temporal depth, phylogenetic scope, and the nonindependence of diversification rate shifts [31].

\section{Analysis of ancestral areas}

The optimal solutions obtained with the DIVA analysis calculated three equally likely possibilities for the distribution of the most recent common ancestor of the Burmanniaceae: 1) the Amazonian Region; 2) the GuineoCongolean and Amazonian Region; 3) the Amazonian and Brazilian Region. Thus despite the lack of resolution to precisely identify the ancestral area of Burmanniaceae, the analysis indicates it was western Gondwanan. According to the second DIVA analysis seven New-Old World dispersals are required to explain the distribution of the terminals. But again, the ancestral area of Burmanniaceae cannot be tracked solely to the paleotropics or neotropics (Figure 1). We assigned seven nodes that may represent dispersal or vicariance events between the neotropics and the paleotropics (Figure 3). Due to the ambiguous optimization of the ancestral areas events 2 and 3 could equally likely be placed on adjacent deeper nodes yet this would still place these events in the same geological epoch.

\section{Discussion}

\section{Divergence time estimates}

The araceous fossil Mayoa portugallica [32] was identified as the most inconsistent calibration point relative to the other calibration points and was therefore not used in the PL analysis, which estimated the node at 64 Mya or $42 \%$ younger than suggested by fossil data. This observation does not necessary imply that the fossil was assigned to a wrong node. There are many possible explanations for this result (for example, error in branch length estimation, failure of the rate smoothing method to comply with the $18 \mathrm{~S}$ rDNA rate heterogeneity, underestimation of the true age by the other fossils as a result of an incomplete fossil record) $[17,33]$. A rerun of the PL analysis revealed that calibration point A had hardly any impact on the age estimations of the Burmanniaceae. With calibration point A included Burmanniaceae age estimations were overall less than $1 \%$ older (results not shown). Apparently the long phylogenetic distance of calibration point A from the Burmanniaceae clade or the influence of calibration points in more closely related clades reduces the impact of this calibration point.

The obtained divergence time estimations of the monocot orders, using a different marker (18S rDNA instead of $r b c L$ ) and considerably fewer taxa, are mostly younger than those published by Janssen and Bremer ([13] see also Table 1). For most orders these differences in age estimations are small. However, the estimations of both crown and stem nodes of some more derived orders (Arecales, Commelinales, and Zingiberales) are considerably younger than those of Janssen and Bremer [13] (Table 1). We attempted to sample the earliest-diverging lineages of each order as well as some more derived taxa. But the much lower taxon sampling in our study compared to the 


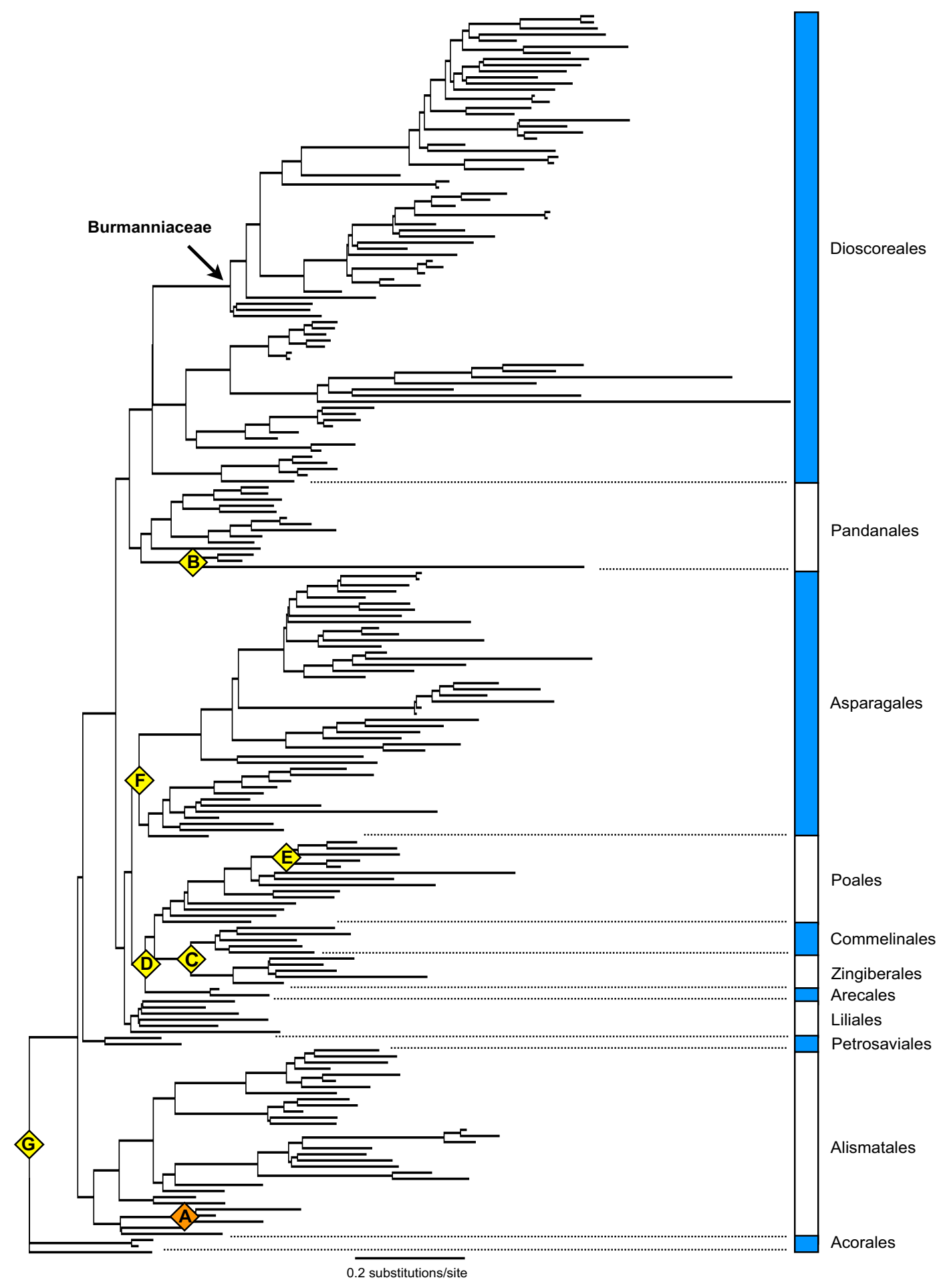

Figure 2

Estimated branch lengths for I8S rDNA phylogenetic analysis of monocots. Bayesian majority-rule consensus tree with optimized branch lengths based on I8S rDNA sequences of 202 monocot taxa and Amborella as outgroup. This tree was used as input for the divergence time estimations with penalized likelihood. The considered calibration points (A-G; see text) are plotted on the tree. 
more than 800 terminals in Janssen and Bremer [13] is likely to have caused an overestimation of the branch that subtends the indicated clades (or underestimation of the branches within these clades) and as a result has led to underestimation of the ages of the crown nodes $[15,16]$. The stem and crown node ages of Dioscoreales are consistent with a recent estimate that used a similar calibration strategy on a two-gene dataset (18S rDNA and atpA) but with fewer taxa [34].

In general the use of secondary calibration points for divergence time estimates is not favored [35]. However, this strategy becomes more sound when the error associated with molecular dating estimates can be transferred into the subsequent divergence time analysis. Here this is coupled with the advantage of accommodating unlinked rate variation across all available loci (a 'multigene' approach). Not unexpectedly, the BEAST analysis results in a chronogram with slightly less branch length heterogeneity than the PL chronogram. 18S rDNA sequences alone do not support a fully resolved Burmanniaceae clade. Artificially resolved clades (by constraints) will result in short branch lengths and more compressed divergence patterns if the data provides insufficient phylogenetic signal to support these clades. This effect seems limited here: the age estimations of the BEAST analysis are not significantly different from those inferred by PL (Figure 3). Node 1 encompasses the most pronounced difference between

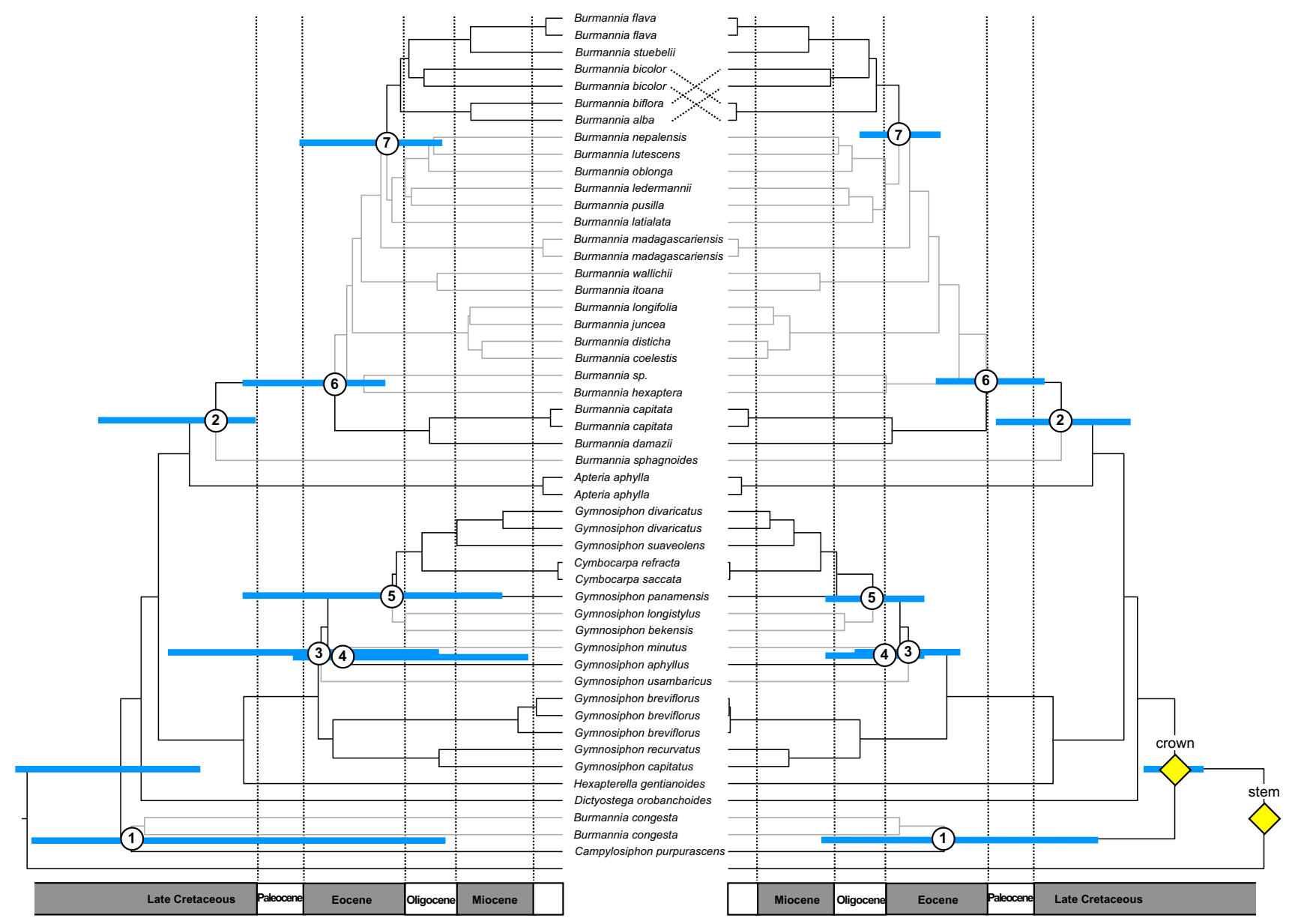

Figure 3

Divergence time estimates of Burmanniaceae. Evolutionary chronograms of Burmanniaceae. The left-side tree is derived from the I8S rDNA Bayesian tree of sampled monocots and the penalized likelihood relaxed molecular clock analysis. From this tree covering all monocot lineages, only the Burmanniaceae clade is shown here. The right-side tree results from the multi-gene BEAST relaxed clock analysis with secondary calibration points. The nodes that were constrained (secondary calibration points) are indicated with yellow squares. Paleotropical lineages are indicated with grey branches, black branches denote neotropical lineages. The nodes labelled I-7 correspond to the origin of New/Old World disjunctions. 
Table I: Age estimation of monocot orders.

\begin{tabular}{|c|c|c|c|c|}
\hline \multicolumn{2}{|c|}{ Order } & \multirow{2}{*}{$\begin{array}{c}\text { Penalized Likelihood age estimations } \\
\text { (in Mya) }\end{array}$} & \multirow{2}{*}{$\begin{array}{c}\text { Credibility intervals } \\
\qquad 1342\end{array}$} & \multirow{2}{*}{$\begin{array}{c}\text { Janssen and Bremer (2004) age } \\
\text { estimations (in Mya) }\end{array}$} \\
\hline Acorales & stem node & & & \\
\hline & crown node & $19 \pm 5.7$ & $7-44$ & \\
\hline \multirow[t]{2}{*}{ Alismatales } & stem node & $128 \pm 1.7$ & $123-133$ & $|3|$ \\
\hline & crown node & $123 \pm 3.9$ & $97-133$ & 128 \\
\hline \multirow[t]{2}{*}{ Petrosaviales } & stem node & $128 \pm 1.9$ & $121-132$ & 126 \\
\hline & crown node & $108 \pm 7.11$ & $87-102$ & 123 \\
\hline \multirow[t]{2}{*}{ Dioscoreales } & stem node & $|2| \pm 2.1$ & $119-130$ & 124 \\
\hline & crown node & $116 \pm 2.6$ & $113-126$ & 123 \\
\hline \multirow[t]{2}{*}{ Pandanales } & stem node & $|2| \pm 2.1$ & $119-130$ & 124 \\
\hline & crown node & $117 \pm 2.4$ & $116-130$ & 114 \\
\hline \multirow[t]{2}{*}{ Liliales } & stem node & $122 \pm 2.6$ & $109-13 \mid$ & 124 \\
\hline & crown node & $118 \pm 6.03$ & $78-|3|$ & 117 \\
\hline \multirow[t]{2}{*}{ Asparagales } & stem node & $122 \pm 4.7$ & $98-126$ & 122 \\
\hline & crown node & $119 \pm 4.1^{4}$ & $101-127$ & 119 \\
\hline \multirow[t]{2}{*}{ Arecales } & stem node & $116 \pm 5.1^{5}$ & $94-122^{3}$ & 120 \\
\hline & crown node & $51 \pm 14.6^{6}$ & $15-98$ & 110 \\
\hline \multirow[t]{2}{*}{ Commelinales } & stem node & $92 \pm 6.8$ & $83-114$ & 114 \\
\hline & crown node & $75 \pm 8.8$ & $50-104$ & 110 \\
\hline \multirow[t]{2}{*}{ Zingiberales } & stem node & $92 \pm 5.5$ & $91-116$ & 114 \\
\hline & crown node & $67 \pm 7.1$ & $52-96$ & 88 \\
\hline \multirow[t]{2}{*}{ Poales } & stem node & $109 \pm 5.2$ & $89-120$ & 117 \\
\hline & crown node & $106 \pm 5.3$ & $88-116$ & 113 \\
\hline
\end{tabular}

Age estimations of monocot orders obtained with PL analysis of I8S rDNA data, including credibility intervals. The age estimations by Janssen and Bremer [13] are listed for comparison.

I The analysis of Janssen and Bremer [13] is based on $878 \mathrm{rbcL}$ sequences. Dating was obtained with nonparametric rate smoothing (NPRS).

2 This node was fixed at 134 Mya.

3 Only one Acorus accession was used in the analysis of Janssen and Bremer [13].

${ }^{4}$ This node was constrained to a minimum age of 93 Mya.

5 This node was constrained to a minimum age of 89.5 Mya.

${ }^{6}$ Only two Arecales accessions were included in the analysis.

the two strategies. While PL assigns this node to the Cretaceous, BEAST favors an Eocene origin, but the credibility intervals on both estimates are large and overlapping.

\section{Biogeography and diversification of Burmanniaceae}

This study points towards a West Gondwanan origin of Burmanniaceae. According to our results the family started to diversify 96.4 Mya (mid-Cretaceous), well before the K/T boundary. The diversification rate shift tests and the LTT plot suggest a high initial diversification rate. Mid-Cretaceous climate was relatively warm [36] although fossil data suggests tropical forests were open and dry adapted and modern closed-canopy rain forest did not originate until after the K/T boundary [37]. However, recent molecular studies suggest that closed-canopy rain forest existed during the mid-Cretaceous [38]. The most recent common ancestor of Burmanniaceae was photosynthetic (see further) and it is possible that initial diversification of the family started when Burmanniaceae lineages became parasitic on arbuscular mycorrhizal fungi as an adaptation to shaded habitats [39]. The separation between South America and Africa has been dated to 105 Mya [12], but the biogeographical timing of this conti- nental breakup is somewhat uncertain because it is unclear when an effective dispersal barrier was established [40]. Furthermore, stepping-stone dispersal routes between South America and Africa may have delayed biogeographical isolation into the Late Cretaceous [41]. Because the Burmannia congesta-Campylosiphon clade is the earliest-diverging lineage in Burmanniaceae one proposed ancestral area of the family includes both neotropics and paleotropics (Figure 1). Under this assumption the separation between Africa and South America is likely to be reflected in the divergence time hypotheses. While such a vicariance event is indeed suggested by the direct dating approach with PL (node $1=94$ Mya), BEAST analysis favours an Eocene divergence (node $1=47 \mathrm{Mya}$ ). Due to the large error associated with both estimates none of the hypotheses can be rejected. A Cretaceous continental drift scenario thus could explain the split between $B$. congesta and Campylosiphon, however, such a vicariance event has been observed only rarely in flowering plants [42-44]. Contrasting this hypothesis, an Eocene boreotropical migration scenario (see further) would be an equally possible explanation for the disjunction observed in node 1 . The DIVA analysis supports a neotropical origin for the 


\section{Proportion of Burmanniaceae sampled $(f)$}

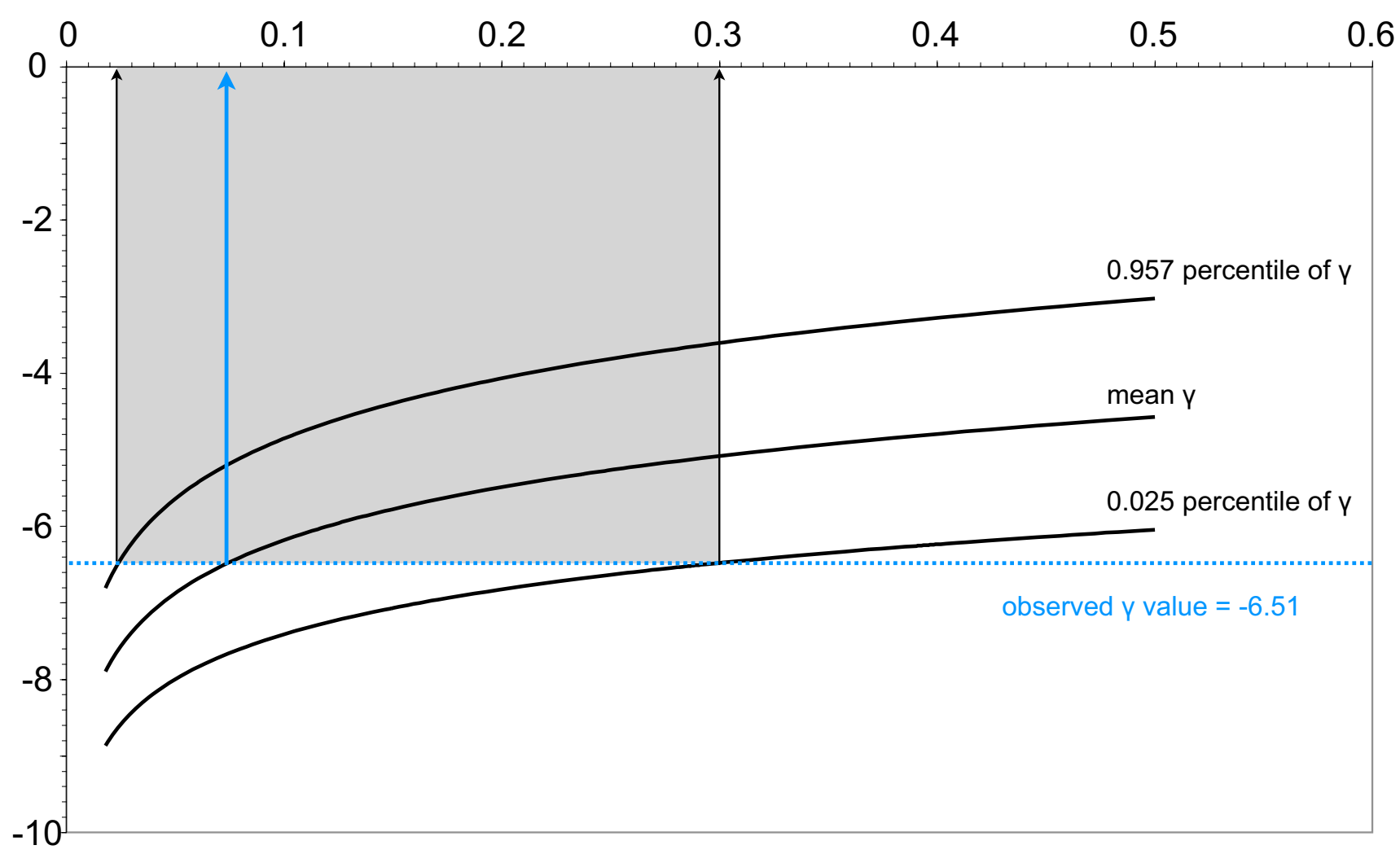

Figure 4

The relationship between $\gamma$ and the proportion of extant taxa in Burmanniaceae $(f)$. We sampled $4 \mathrm{I}$ species of Burmanniaceae and measured a $\gamma$-value of $-6.5 \mathrm{I}$ using the BEAST chronogram (blue dotted line). To explore the effects of missing lineages we generated $\gamma$-statistic values under the assumption that our sampling $n(n=4 I)$ represents only a proportion $(f)$ of the extant Burmanniaceae species. The three curves show the mean, 0.975 percentile, and 0.025 percentile of the $\gamma$-distribution. This distribution was constructed by calculating $\gamma$ of 1000 simulated pure-birth phylogenies with $n / f$ tips, each randomly pruned to $4 \mathrm{I}$ tips, for values of $f$ ranging from 0.018 to 0.5 . To measure a $\gamma$-value of $-6.5 \mathrm{I}$ using $4 \mathrm{I}$ taxa while the actual value is not significantly different from zero, Burmanniaceae should contain 562 lineages (95\% Cl: I39-I 708). Currently 92 Burmanniaceae species are known [60].

clade containing all other Burmanniaceae lineages. The Malaysian species, Burmannia sphagnoides branched off from its neotropical predecessors 75 Mya (PL) - 72 Mya (BEAST) ago (Figure 3, node 2). Migration between Gondwana and Laurasia in the Late Cretaceous could have been possible through land connections allowing the interchange of taxa between South America, India, and Madagascar $[12,45,46]$. Furthermore, India may have acted as a raft that transported some taxa from Madagascar to Asia [47]. Both phenomena together could well explain the biogeographical history of $B$. sphagnoides.

The Late Cretaceous and Paleocene are characterized by a decrease in diversification rates (Figure 5). This slowdown may have resulted from decreased origination rates (e.g. filling ecological niches, [48]), and/or from increased extinction rates. The latter hypothesis is coincident with the occurrence of the K/T mass-extinction $[49,50]$. A subsequent increase of the diversification rate, associated with the diversification Burmannia and Gymnosiphon, occurred at the Late Paleocene and through the Eocene. Simultaneously lineages of both genera reached the Old World (Figure 3). These events are well correlated with a boreotropical dispersal scenario as proposed for other tropical angiosperm families $[18,23,25-28]$. According to this scenario South American taxa of Burmannia and Gymnosiphon are hypothesized to have migrated via scattered, continental and/or volcanic islands that connected North and South America at various times during the Tertiary [23]. From North America migration across Laurasia in to the Old World could continue via a series of connections across the North Atlantic ('North Atlantic Land Bridge' 


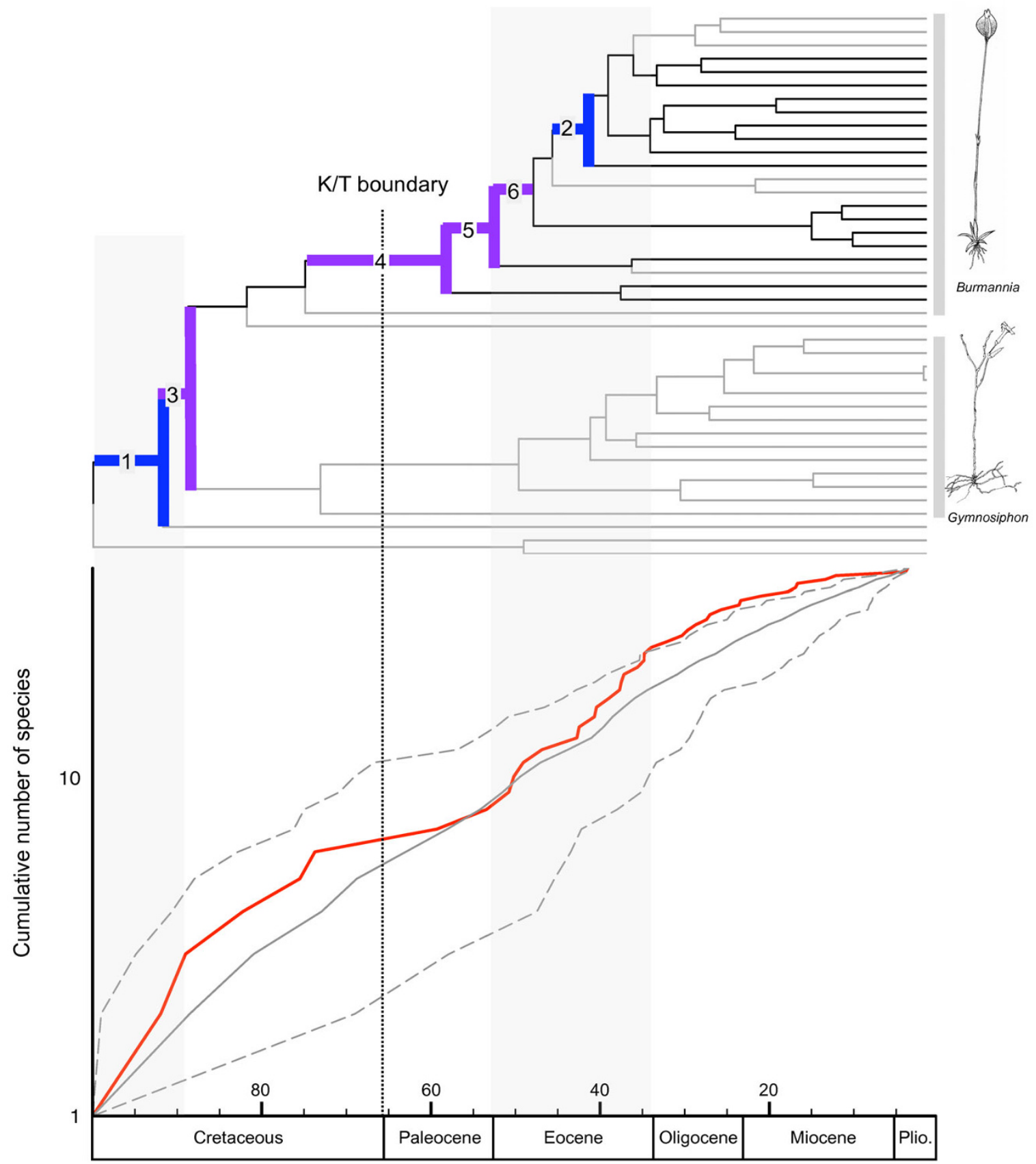

Millions of years before present

\section{Figure 5}

Estimated timing and tempo of diversification in Burmanniaceae. (a) BEAST chronogram of the ingroup with multiple accessions for the same species excluded. Grey branches indicate achlorophyllous species. Branches with significant diversification rate shifts are numbered; shifts I and 2 are supported by $\Delta \mathrm{I}, \Delta 2$, and Slowinski and Guyer statistics; shifts 3-6 are supported by the relative cladogenesis statistic. Burmannia (excluding B. congesta) and Gymnosiphon clades are highlighted with grey bars, with two drawings of specimens as exemplars. (b) Semilogarithmic lineage-through-time (LTT) plot of Burmanniaceae (red) and simulated LTT plot with $95 \%$ confidence intervals (grey) with a constant death-birth rate of 0.5 . Upturns or downturns in the empirical LTT plot reflect changes in diversification rate. Prolonged periods of increased diversification rate are highlighted by shaded areas. 
[23,51]. Further diversification into Africa, Madagascar, and Asia would explain the current distribution patterns of these genera. Laurasian migration of tropical groups was facilitated by warm and humid climates that occurred during the Eocene [52]. Particularly at the beginning of the Eocene global temperatures peaked and plants with tropical affinities grew at middle and high latitudes $[53,54]$. This is also the reason why an eastern migration through Beringia, which did not support tropical vegetation, seems unlikely $[23,26]$. Significant cooling during the Oligocene caused a retraction of the boreotropical flora from across the North Atlantic [55]. This cooling, which started at the end of the Eocene [51], probably caused a 'climatic' vicariance in Burmannia and Gymnosiphon: as both distributions moved southwards they became separated into New and Old World groups (Figure 3, nodes 5 and 7). According to our results, no migration between the neotropics and paleotropics occurred for the remaining $\approx 30 \mathrm{My}$, illustrating the limited long-distance dispersal capabilities of Burmanniaceae species. Simultaneously with the Oligocene cooling the LTT plot shows the start of a gradual decrease of the diversification rate towards the present. An overall decrease in lineage accumulation for Burmanniaceae is also suggested by the CR test.

\section{Loss of chlorophyll}

One of the most intriguing features of Burmanniaceae is the absence of chlorophyll in most taxa, except for some Burmannia species. Almost nothing is known about the chloroplast genome in achlorophyllous Burmanniaceae or myco-heterotrophic plants in general. Studies on the chloroplast genome of parasitic plants reported the loss of most chloroplast genes [56,57]. If we assume that the chloroplast genes in myco-heterotrophic Burmanniaceae undergo the same fate, then a reversal to autotrophy seems highly improbable. With this assumption, at least eight independent losses of chlorophyll took place in Burmanniaceae (Figure 5). As each lineage may have lost its chlorophyll independently, it is difficult to speculate about the age of these events. According to a most-parsimonious pattern, the ancestral lineage leading to the Gymnosiphon-Hexapterella clade lost its photosynthesis during the Late Cretaceous. The evolution from a mycorrhizal photosynthetic plant towards a non-photosynthetic myco-heterotroph has been explained as a phenomenon that can provide escape from competitive exclusion in the shaded conditions of forest understory habitats [39]. A Late Cretaceous origin of myco-heterotrophy thus provides evidence for the presence of closed-canopy environments before the K/T boundary [38]. The chlorophyll losses in the core Burmannia clade would have occurred during the Eocene and the Oligocene, when closed-canopy rain forest was abundant even at low latitudes $[53,58]$. While Burmannia species seem to have lost their chlorophyll after crossing the North Atlantic Land Bridge, a single loss event in the Gymnosiphon clade would have occurred before their Laurasian migration. This result suggests that achlorophyllous plant species were able to migrate and diversify long after their adaptation to a myco-heterotrophic nutrition strategy.

\section{Conclusion}

In his excellent monograph of the Burmanniaceae Jonker [10] wrote: "Fossil Burmanniaceae are unknown. The family however is very old, according to the occurrence of closely related species in America, Africa, and Asia [...]". Our analyses reveal that Burmanniaceae are a relatively old family, and vicariance events possibly influenced the early diversification of the family. Our study also suggests that the diversification and radiation of the pantropical genera Burmannia and Gymnosiphon started from South America during the Eocene when continental drift had separated South America from Africa. The global temperature during that epoch was high enough to allow tropical rain forests to expand significantly. This triggered an increased diversification in Burmannia and Gymnosiphon and allowed for boreotropical migration across the North Atlantic Ocean in to the Old World for both genera. Our results imply that the increase of neotropical plant diversity during the Eocene [58] and the boreotropical migration of tropical plants [23-29] also applies to mycoheterotrophic plants.

\section{Methods}

\section{Molecular data}

This study samples 41 species of Burmanniaceae, covering seven of the nine genera $[10,59,60]$. Only the monospecific neotropical genera Marthella and Miersiella are not represented. For Burmannia our sampling includes 23 of the approximately 60 described species (38\%), for Gymnosiphon 12 species of 24 known species were available $(50 \%)[60]$. With species from the New World, Africa, and Asia our sampling covers the current geographic distribution range of both genera. For the phylogenetic inference of Burmanniaceae, sequence data of Pandanus tectorius (Pandanales) were used as outgroup. Herbarium vouchers and GenBank accessions for the taxa used in this study are listed in Additional file 1.

Sequence data of $18 \mathrm{~S}$ rDNA and nad $1 b$-c from a previous study [61] were supplemented with additional sequences. For most species ITS data was obtained using the following protocol. DNA was extracted from silica dried and herbarium material with the PureGene DNA extraction kit (Gentra Systems, Landgraaf, The Netherlands) following the manufacturer's instructions. The nuclear $18 \mathrm{~S}$ rDNA region and the mitochondrial nad $1 b-c$ intron were amplified following Merckx et al. [61]. Amplification of the nuclear ITS region was carried out with the primers ITS1 
and ITS4 [62], with a premelt of $5 \mathrm{~min}$ at $94^{\circ} \mathrm{C}$, followed by 30 cycles of $30 \mathrm{~s}$ of denaturation at $94^{\circ} \mathrm{C}, 30 \mathrm{~s}$ annealing at $55^{\circ} \mathrm{C}, 1 \mathrm{~min}$ extension at $72^{\circ} \mathrm{C}$, and a $7 \mathrm{~min}$ final extension at $72^{\circ} \mathrm{C}$. All PCR products were cleaned with the Nucleospin Extract II columns (Machery-Nagel, Düren, Germany) following manufacturer's instructions. Sequencing reactions were run on an ABI 310 automated sequencer (Applied Biosystems, Fostercity, USA). Some samples were sequenced by the Macrogen sequencing facilities (Macrogen, Seoul, South Korea). Sequencing files were edited and assembled using Staden for Mac OS $\mathrm{X}$ [63].

Due to contamination with fungal DNA no ITS data could be obtained for three taxa: Burmannia sphagnoides, Gymnosiphon suaveolens, and G. panamensis. In the nad1 $b-c$ dataset sequences of $B$. nepalensis and C. saccata are missing. The nad1 b-c sequence of C. saccata (DQ786096) was not used as this sequence probably belongs to a Gymnosiphon species.

Alignment was done by eye using MacClade 4.04 [64]. Gaps in the nad1 $b$ - $c$ intron data were coded using the simple indel coding method (SIC; [65]) as implemented in SeqState [66]. Autapomorphic indel characters were manually removed from the dataset.

\section{Phylogenetic analyses}

Molecular data were analyzed using maximum parsimony and Bayesian methods. Each of the three data partitions (18S rDNA, ITS, and nad 1 b-c [including indel characters]) was analyzed separately. Since no strongly supported (>85\% bootstrap percentage/>95\% Bayesian posterior probability) incongruences were observed between the topologies, combined analyses of the molecular data were performed. Maximum parsimony (MP) analyses were done with PAUP* v4b10 [67] using a heuristic search with the TBR branch swapping algorithm for 1,000 replicates, holding 5 trees at each step and with the Multrees option in effect. Branch stability was calculated using a bootstrap analysis with 1,000 pseudo-replicates. For each replicate a heuristic search was conducted with the same settings as described above. Model selection for the Bayesian analyses was done using Modeltest v3.06 [68]. For all tree genes Modeltest selected the GTR+I+G model. For the indel data we selected the restriction site model as recommended in the MrBayes 3.1 manual [69]. The combined analyses were performed with a partitioned model approach. Bayesian analyses were run on the K.U. Leuven UNIX cluster ('VIC') using MrBayes 3.1.2 [70,71]. Each analysis was run three times for three million generations sampling every 1,000 generations. The first $50 \%$ of the sampled trees were treated as burnin and discarded. The sump command in MrBayes was used to check whether the two separate analyses converged on similar log-likelihoods. Additionally convergence of the chains was checked using TRACER 1.4 [72] and the effective sampling size (ESS) parameter was found to exceed 100, which suggests acceptable mixing and sufficient sampling.

\section{Divergence time estimation}

Burmanniaceae and Dioscoreales in general are absent from the fossil record [73] and because our sampling does not allow dating based on geographic history (e.g. volcanic islands), it is impossible to calibrate the Burmanniaceae tree directly. To estimate ages of nodes in the Burmanniaceae phylogeny we expanded our phylogeny to comprise all monocot lineages. This allowed the incorporation of multiple fossil calibration points, in order to minimize bias produced by single calibration points. An additional purpose was to have fossils calibrating nodes at different distances to the root of the phylogeny, averaging out any biases that might result from calibrating at different levels in the phylogeny. To this end we extended our $18 \mathrm{~S}$ rDNA sampling with $18 \mathrm{~S}$ rDNA accessions from GenBank of all monocot orders and Amborella as outgroup [see Additional file 1]. This dataset of 203 taxa and 1662 characters was analyzed with MrBayes using the following constraints: (1) all monocot orders were forced to be monophyletic; (2) the relationships between the orders was constrained according to the multi-gene monocot topology by Chase [74], and (3) the relationships between the Burmanniaceae taxa were constrained to the multi-gene tree presented in this study. The Bayesian analysis was run for five million generations, sampling every 1,000 generations, and using the GTR $+\mathrm{I}+\mathrm{G}$ model as selected by the AIC implemented in Modeltest 3.06. A majority-rule consensus tree with branch lengths averaged over the last 2,500 trees (50\%) was obtained with the sumt command. Branch lengths of this majority-rule consensus tree were then optimized with MrBayes under the GTR+I+G model by setting the proposal probability ('props') of the 'node slider' to 5 and the proposal probability of all other topology moves to 0 [69]. Because MrBayes requires a fully resolved starting tree polytomies in the majority-rule consensus tree were arbitrarily resolved. The MCMC was run over two million generations, sampling every 1,000 generations. A majority rule tree was calculated over the last 1,000 sampled trees (Figure 1$)$. Because a $\chi^{2}$ likelihood ratio test strongly rejected a strict molecular clock for our data $\left(\chi^{2}=1316.36\right.$; $\mathrm{df}=$ $\left.201 ; \mathrm{P}=6.6 \times 10^{-150}\right)$, we applied a relaxed clock model, using penalized likelihood (PL) analysis as implemented in r8s [75] to obtain age estimations. Seven calibration points were used to calibrate the $18 \mathrm{~S}$ rDNA tree (Figure 2). A: a minimum age constraint of the stem node of Monsteroideae (Araceae) of 110 Mya. This is consistent to the minimum age of Mayoa portugallica, an araceous fossil assigned to the tribe Spathiphylleae [32]. B: a minimum age constraint of 90 Mya to the crown node of Triuri- 
daceae. This is based on the Triuridaceae fossil flowers Mabelia and Nuhliantha from the Upper Cretaceous [76]. Phylogenetic analyses of morphological data showed that both fossil genera are nested within extant Triuridaceae. Our sampling includes two species of Sciaphila and one Kupea species. The latter genus was shown to be the basally-divergent node of Triuridaceae [77]. C: the minimum age of the split between Zingiberales and Commelinales constrained to 83 Mya $[78,79]$. D: the stem node age of the Arecaceae constrained to a minimum of 89.5 Mya $[79,80]$. E: the crown node of the Flagellariaceae/ Poaceae/Joinvilleaceae/Restionaceae clade constrained to a minimum age of $69.5 \mathrm{Mya}[79,81]$. F: a minimum age of 93 Mya for the Asparagales crown node based on the minimum age of fossil Liliacidites pollen [82]. G: all calibration points listed above are fossil data and therefore apply minimum ages only. However, the r8s software requires at least one fixed calibration point. In order to achieve this we considered a fixed crown node age of the monocots of 134 Mya, an estimate obtained by Bremer [79]. This age is consistent with results obtained by other studies [83-85]. We used the 'fossil cross-validation' method to measure the agreement between these different calibration points [17]. This method compares the difference between the fossil and molecular ages by rerunning the PL analysis with single calibration nodes. The summed square (SS) values of the deviations between molecular age estimations and the fossil constraint's age for each node are plotted in Figure 6. Calibration point A exhibited the largest SS. Removal of this calibration point resulted in a twofold decrease of the average squared deviation $(s)$ of all remaining fossils (Figure 7). Subsequent removal of the other fossil calibrations had no impact on the magnitude of $s$. Fossil constraint A was therefore identified as the

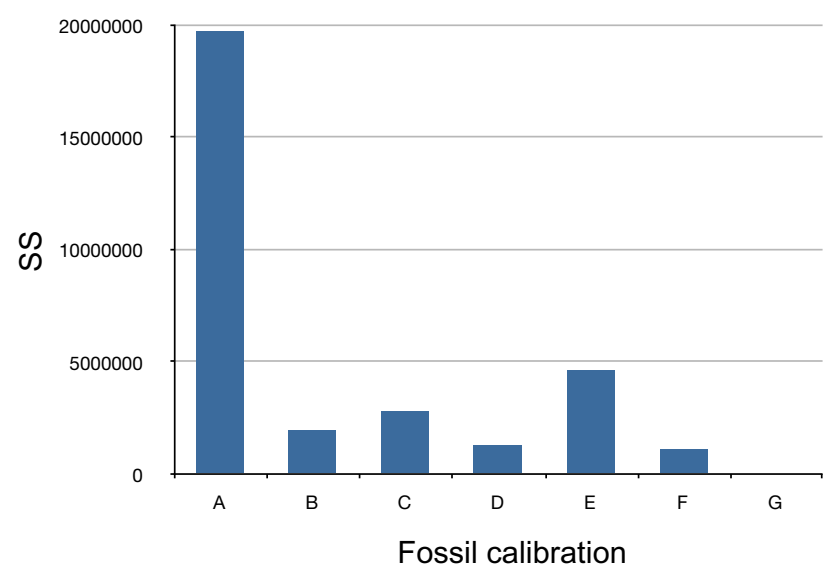

\section{Figure 6}

Consistency of calibration points. Histogram of the summed square values of the deviations between molecular and fossil ages (SS) for each calibration point.

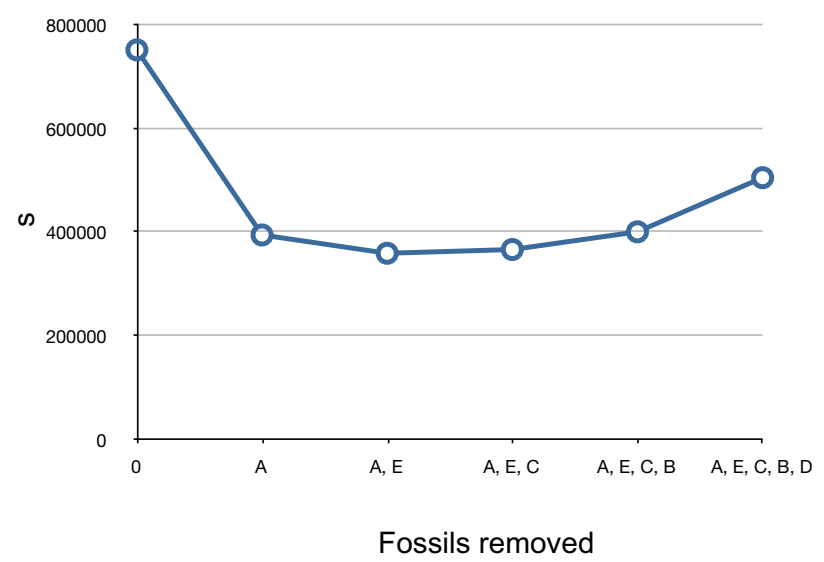

Figure 7

Effect of calibration point removal. Plot illustrating the effect of removing fossil calibration points on the average squared deviation (s).

most inconsistent calibration point and omitted from the analyses.

The rooted Bayesian majority-rule consensus tree with optimized branch lengths was used as the input tree for a penalized likelihood (PL) analysis with r8s $1.70[75,86]$. As suggested by the author, the truncated-Newton (TN) optimization algorithm was selected for the analyses. The rate smoothing penalty parameter was set to $1.3 e^{2}$ as determined by the statistical cross-validation method implemented in r8s 1.70. Standard deviations and credibility intervals on the age estimations were calculated by reapplying PL to 1,000 randomly chosen trees kept from the Bayesian analysis.

Additionally we performed a Bayesian relaxed clock analysis with all three data partitions using BEAST 1.4.6 [87]. We applied a GTR+I+G model with 4 gamma categories on each partition following the 'BEAST partitioning manual' [88]. The uncorrelated lognormal clock model [20] was selected and two secondary calibration points and the credibility intervals were taken from the r8s analysis described above: a prior of $116.3 \pm 2.6$ Mya was set for the root of the tree and a prior of $96.0 \pm 3.4$ Mya for the crown node of the Burmanniaceae. In the BEAST analysis a normal distribution was applied to reflect the credibility intervals produced by reapplying PL to 1,000 trees. The distribution of all other priors was set to uniform. Posterior distributions of parameters were approximated using two independent Markov chain Monte Carlo analyses of twenty million generations followed by a discarded burnin of 2,000,000 generations (10\%). Convergence of the chains was checked using TRACER 1.4 [72] and the effective sampling size (ESS) parameter was found to 
exceed 100, which suggests acceptable mixing and sufficient sampling. The XML BEAST input file is available from the first author on request.

\section{Tempo of diversification}

We evaluated the tempo of lineage accumulation in Burmanniaceae using the constant-rate (CR) test [30]. This test uses the $\gamma$-statistic to compare the relative positions of the nodes in the chronogram to those expected under a $\mathrm{CR}$ model of diversification. A negative value of the $\gamma$-statistic indicates that that nodes are closer to the root than expected under a CR model and implies a deceleration in the accumulation of lineages. A positive value indicates that nodes are closer to the tips than expected under a CR model and implies an acceleration of lineages [30]. A CR model of diversification can be rejected at the $95 \%$ level if $\gamma<-1.645$ [30]. We calculated the gamma-statistic of the BEAST chronogram of the ingroup with duplicate species excluded. However, the $\gamma$-statistic is biased by extinction, because older lineages have higher risks of being extinct at present than younger ones (bias towards positive $\gamma$ values), and by incomplete taxon sampling, because nodes near the root of the tree give rise to more extant descendants than nodes near the tips and are therefore more likely to be included in a small random sample (bias towards negative $\gamma$ values) $[89,90]$. To explore the effects of incomplete taxon sampling on the $\gamma$-statistic calculated on the Burmanniaceae chronogram we simulated pure-birth (d:b =0) trees with Phylogen 1.1 [91] under the assumption that our Burmanniaceae sampling $n(n=41)$ represents only a proportion $(f)$ of the actual diversity $[92,93] .1,000$ pure-birth trees were simulated with $\mathrm{n} / f$ tips for $f$ values ranging from 0.018 to 0.5 . This corresponds to an extant Burmanniaceae diversity ranging from 82 to 2278 species. Each tree was then randomly pruned to 41 tips and the $\gamma$ statistic was calculated. For each simulated dataset of 1000 phylogenies the mean value of $\gamma$ and the $95 \%$ confidence interval were plotted to estimate the 95\% confidence interval for the number of lineages that must be missing to obtain a $\gamma$-statistic as extreme as the measured one if $\gamma$ actually is zero [93]. The resulting curves are shown in Figure 4. All $\gamma$-statistics were calculated with Genie 3.0 [94].

\section{Lineage-through-time plot}

A lineage-through-time (LTT) plot of the BEAST chronogram without doublet species was constructed with ENDEPI [95]. Our sampling consisted of $\approx 45 \%$ of described Burmanniaceae lineages (41 out of 92 species [60]). To evaluate the effects of incomplete taxon sampling on the slope of the LTT plot, we generated 1,000 phylogenies with 92 taxa under a death-birth ratio of 0.5 , and randomly pruned each tree to 41 taxa. The branch lengths of the resulting trees were scaled with TreeEdit 1.0 [95] to set the root node of each tree 96.4 My from the tips (the crown node age of the Burmanniaceae estimated using BEAST). The scaled trees were used to construct a mean LTT curve with $95 \%$ confidence intervals. To evaluate the fit of the empirical LTT plot to three general models of diversification (A, B, and $\mathrm{C}[97,98])$ we used the different survival models implemented in the APE 1.8 package $[97,99]$. Model A assumes a constant diversification rate; Model B assumes a monotonically changing diversification rate. The parameter that controls the change of this rate is called $\gamma$. If $\gamma$ is greater than one, then the diversification rate decreases through time. Model $\mathrm{C}$ assumes an abrupt change in rate before and after some breakpoint in the past. See McKenna \& Farrell [98] for a visual comparison between these models. For model C, optimal time points for a shift in rate of diversification suggested by the LTT plot were tested. To detect and locate significant diversification rate shifts we used the $\Delta 1, \Delta 2$, and the Slowinski and Guyer (SG) [99] statistic (implemented in SymmeTREE 1.1 [100]), and the relative cladogenesis (RC) test (implemented in END-EPI).

\section{Analysis of ancestral areas}

We estimated ancestral areas of Burmanniaceae with a dispersal-vicariance analysis using DIVA 1.1 [101]. Species distributions were scored using floristic regions as described by Takhtajan [102]. The ingroup taxa used in this study are distributed over 12 regions: Guineo-Congolian Region, Sudano-Zambezian Region, Madagascan Region, Indian Region, Indochinese Region, Malaysian Region, Caribbean Region, Amazonian Region (including Guyana Highlands), Brazilian Region, Eastern Asiatic Region, Northeast Australian Region, North American Atlantic Region. The number of unit areas allowed in ancestral distributions was restricted to two with the maxareas option in DIVA. To estimate the number of dispersals between the New and Old World the DIVA analysis was repeated with the terminals scored for presence in either the New World or the Old World.

\section{Abbreviations}

18S rDNA: Nuclear small subunit ribosomal DNA; AIC: Akaike information criterion; CR test: Constant rate test; GTR: General time reversible model (a model of DNA sequence evolution); hLRT: Hierarchical likelihood ratio test; I + G: Invariant sites plus gamma distribution; ITS: Internal transcribed spacer; LTT plot: Lineage-throughtime plot; MCMC: Markov chain Monte Carlo (a simulation method used to approximate the posterior probability of trees); nad1 $b-c$ : The intron between the b and $\mathrm{c}$ exons of subunit one of the mitochondrial gene for NADH dehydrogenase; PL: Penalized likelihood; RC test: Relative cladogenesis test; SG statistic: Slowinski and Guyer statistic. 


\section{Authors' contributions}

VM conceived the study, gathered the molecular data, carried out the analyses, and wrote and edited the manuscript. LWC participated in the design of the study, helped with the analyses and writing of the manuscript. BL participated in the molecular study and the sequence alignment. MNS collected samples and helped drafting the manuscript. SH contributed to the data interpretations and writing of the manuscript. EFS participated in the coordination of the study and helped drafting the manuscript. All authors read and approved the final manuscript.

\section{Additional material}

\section{Additional file 1}

GenBank accessions. List of voucher numbers and Genbank accession numbers.

Click here for file

[http://www.biomedcentral.com/content/supplementary/14712148-8-178-S1.doc]

\section{Acknowledgements}

The authors thank Joep Moonen, Michel De Bont, Marcus Etonge, Steven Dessein, Renske Ek, Thassilo Franke, William Hahn, Robert Harwood, Carel Jongkind, Kun-Ping Lo, Ray Neyland, Dan Nickrent, Axel Poulsen, Piet Ruijters, Sofie Ruysschaert, Inge Van Der Linden, Carel Jongkind, Olaf Banki, Paul Maas, Hiltje Maas, and Stephan Imhof for support during collection trips or sending plant material. We are also grateful to Steven Janssens, Jan De Laet and Peter Schols for technical assistance. Susanne Renner and an anonymous reviewer provided helpful comments on earlier versions of this manuscript. VM has a research grant from the Institute for the Promotion of Innovation through Science and Technology in Flanders (IWT Vlaanderen, no. 31536). General financial support was provided by the K.U. Leuven (OT/05/35) and FWO (G.04/8.08).

\section{References}

I. Cheek M, Williams S: A review of African saprophytic flowering plants. In African plants: biodiversity, taxonomy Edited by: Timberlake J, Kativu S. Kew: Royal Botanic Gardens; 1999:39-49.

2. Zhang D, Saunders RMK, Hu C: Corsiopsis chinensis gen. et sp. nov. (Corsiaceae): first record of the family in Asia. Syst Bot 1999, 24:3||-3|4.

3. Sasidharan N, Sujanapal P: Rediscovery of Haplothismia exannulata Airy Shaw (Burmanniaceae) from its type locality. Rheedea 2000, I0:131-134.

4. Woodward C, Berry PE, Maas-van de Kamer H, Swing K: Tiputinia foetida, a new mycoheterotrophic genus of Thismiaceae from Amazonian Ecuador, and a likely case of deceit pollination. Taxon 2007, 56:157-162.

5. Leake JR: The biology of myco-heterotrophic ('saprophytic') plants. New Phytol 1994, I 27:171-216.

6. Bidartondo MI, Redecker D, Hijri I, Wiemken A, Bruns TD Domínguez L, Sérsic A, Leake JR, Read DJ: Epiparasitic plants specialized on arbuscular mycorrhizal fungi. Nature 2002 419:389-392.

7. Franke T, Beenken L, Döring M, Kocyan A, Agerer R: Arbuscular mycorrhizal fungi of the Glomus-group A lineage (Glomerales; Glomeromycota) detected in myco-heterotrophic plants from tropical Africa. Mycol Progress 2006, 5:24-31.

8. Maas PJM, Ruyters P: Voyria and Voyriella (saprophytic Gentianaceae). Flora Neotropica 1986, 41:1-93.
9. Malme GOA: Die Burmannien der ersten Regnel'schen Expedition. Bih Kongl Svenska Vetensk-Akad Handl 1896, 22:I-32.

10. Jonker FP: A monograph of the Burmanniaceae. Meded Bot Mus Herb Rijksuniv Utrecht 1938, 5 I: I-279.

II. Raven PH, Axelrod DI: Angiosperm biogeography and past continental movements. Ann Miss Bot Gard 1974, 6 1:539-673.

12. McLoughlin S: The breakup history of Gondwana and its impact on pre-Cenozoic floristic provincialism. Aust $J$ Bot 200I, 49:27I-300.

13. Janssen $\mathrm{T}$, Bremer $\mathrm{K}$ : The age of major monocot groups inferred from 800+ rbcL sequences. Bot J Linn Soc 2004, I 46:385-398.

14. Sanderson MJ, Doyle JA: Sources of error and confidence intervals in estimating the age of angiosperms from rbcL and I8S rDNA data. Am J Bot 200I, 88:1499-1516.

15. Linder HP, Hardy CR, Rutschmann F: Taxon sampling effects in molecular clock dating: an example from the African Restionaceae. Mol Phylogenet Evol 2005, 35:569-582.

16. Pirie MD, Chatrou LW, Erkens RHJ, Maas JW, Niet T van der, Mols JB, Richardson JE: Phylogeny reconstruction and molecular dating in four Neotropical genera of Annonaceae: the effect of taxon sampling in age estimations. In Plant species-level systematics: new perspectives on pattern \& process. Regnum Vegetabile 143 Edited by: Bakker FT, Chatrou LW, Gravendeel B, Pelser PB. Liechtenstein: A.R.G. Gantner Verlag, Ruggell; 2005:I49-I74.

17. Near TJ, Sanderson MJ: Assessing the quality of molecular divergence time estimates by fossil calibrations and fossilbased model selection. Philos Trans R Soc Lond B Biol Sci 2004 , 359(I450): | 477-| 483.

18. Muellner AN, Savolainen V, Samuel R, Chase MW: The mahogany family "out of Africa": divergence time estimation, global biogeographic patterns inferred from plastid rbcL DNA sequences, extant, and fossil distribution of diversity. Mol Phylogenet Evol 2006, 40:236-250.

19. Graur D, Martin W: Reading the entrails of chickens: Molecular timescales of evolution and the illusion of precision. Trends Genet 2004, 20:80-86.

20. Drummond AJ, Ho SYW, Phillips MJ, Rambaut A: Relaxed phylogenetics and dating with confidence. PLOS Biol 2006, 4:e88.

21. de Queiroz A: The resurrection of oceanic dispersal in historical biogeography. Trends Ecol Evol 2005, 20:68-73.

22. Renner SS: Relaxed molecular clocks for dating historical plant dispersal events. Trends Plant Sci 2005, I O(I I ):550-558.

23. Davis CC, Bell CD, Mathews S, Donoghue MJ: Laurasian migration explains Gondwanan disjunctions: evidence from Malpighiaceae. Proc Natl Acad Sci USA 2002, 99:6833-6837

24. Givnish TJ, Millam KC, Evans TM, Hall JC, Pires JC, Berry PE, Sytsma $\mathrm{KJ}$ : Ancient vicariance or recent long-distance dispersal? Inferences about phylogeny and South American-African disjunctions in Rapateaceae and Bromeliaceae based on ndhF sequence data. Int J Plant Sci 2004, I 65:S35-S54.

25. Smedmark JEE, Anderberg A: Boreotropical migration explains hybridization between geographically distant lineages in the pantropical clade Sideroxyleae (Sapotaceae). Am J Bot 2007, 94:|49|-1505.

26. Weeks A, Daly DC, Simpson BB: The phylogenetic history and biogeography of the frankincense and myrrh family (Burseraceae) based on nuclear and chloroplast sequence data. Mol Phylogenet Evol 2004, 35:85-I0I.

27. Renner SS, Clausing G, Meyer K: Historical biogeography of Melastomataceae: the roles of Tertiary migration and longdistance dispersal. Am J Bot 200I, 88: I290-I300.

28. Zerega NJC, Clement WL, Datwyler SL, Weiblen GD: Biogeography and divergence times in the mulberry family (Moraceae). Mol Phylogenet Evol 2005, 37:402-4I6.

29. Särkinen TE, Newman MF, Maas PJM, Maas H, Poulsen AD, Harris DJ, Richardson JE, Clark A, Hollingsworth M, Pennington RT: Recent oceanic long-distance dispersal and divergence in the amphiAtlantic rain forest genus Renealmia L.f. (Zingiberaceae). Mol Phylogenet Evol 2007, 44:968-980.

30. Pybus OG, Harvey $\mathrm{PH}$ : Testing macro-evolutionary models using incomplete molecular phylogenies. Proc R Soc B 2000, 267:2267-2272

31. Moore BR, Chan KMA, Donoghue MJ: Detecting diversification rate variation in supertrees. In Phylogenetic supertrees: combining 
information to reveal the tree of life Edited by: Bininda-Emonds ORP. Dordrecht: Kluwer Academic; 2004:487-533.

32. Friis EM, Pedersen KR, Crane PR: Araceae from the early Cretaceous of Portugal: evidence on the emergence of monocotyledons. Proc Natl Acad Sci U S A 2004, I 01 : 16565-16570.

33. Rutschmann F: Molecular dating of phylogenetic trees: a brief review of current methods that estimate divergence times. Diversity Distrib 2006, I 2:35-48.

34. Merckx V, Bidartondo Ml: Breakdown and delayed cospeciation in the arbuscular mycorrhizal mutualism. Proc $R$ Soc B 2008, 275: 1029-1035.

35. Shaul S, Graur D: Playing chicken (Gallus gallus): methodological inconsistencies of molecular divergence date estimates due to secondary calibration points. Gene 2002, 300:59-61.

36. Wilson PA, Norris RD: Warm tropical ocean surface and global anoxia during the mid-Cretaceous period. Nature 200I, 4I 2:425-429.

37. Wolfe JA, Upchurch GR: North American nonmarine climates and vegetation during the Late Cretaceous. Palaeogeography, Palaeoclimatology, Palaeoecology 1987, 61:33-77.

38. Davis CC, Webb CO, Wurdack KJ, Jaramillo CA, Donoghue MJ Explosive radiation of Malpighiales supports a mid-Cretaceous origin of modern tropical rain forests. Am Nat 2005, 165:E36-E65.

39. Bidartondo MI, Burghardt B, Gebauer G, Bruns TD, Read DJ: Changing partners in the dark: isotopic and molecular evidence of ectomycorrhizal liaisons between forest orchids and trees. Proc R Soc B 2004, 27 I: I799-I806.

40. Bremer K, Janssen T: Gondwanan origin of major monocot groups inferred from dispersal-vicariance analysis. In Monocots: comparative biology and evolution. Aliso 22 Edited by: Columbus JT, Friar EA, Hamilton CW, Porter JM, Prince LM, Simpson MG. Claremont: Rancho Santa Anna Botanic Garden; 2006:22-27.

4I. Raven PH, Axelrod DI: Plate tectonics and Australasian paleobiogeography. Science 1972, 176:1379-1386.

42. Chanderbali AS, Werff $H$ Van Der, Renner SS: Phylogeny and historical biogeography of Lauraceae: evidence from the chloroplast and nuclear genomes. Ann Miss Bot Gard 2002, 88: $104-134$

43. Richardson JE, Chatrou LW, Mols JB, Erkens RHJ, Pirie MD: Historical biogeography of two cosmopolitan families of flowering plants: Annonaceae and Rhamnaceae. Phil Trans R Soc B 2004 359: $1495-1508$

44. Renner S, Won $\mathrm{H}$ : Repeated evolution of dioecy from monoecy in Siparunaceae. Syst Biol 200I, 50:700-7I2.

45. Veevers JJ, Powell C, Roots SR: Review of sea floor spreading around Australia. I. Synthesis of the patterns of spreading. Afr Earth Sci 1991, 38:373-389.

46. Van Bocxlaer I, Roelants K, Biju SD, Nagaraju J, Bossuyt F: Late Cretaceous vicariance in Gondwanan amphibians. PLoS ONE 2006 I:e74.

47. Morley RJ: Palynological evidence for Tertiary plant dispersals in the SE Asian region in relation to plate tectonics and climate. In Biogeography and Geological Evolution of SE Asia Edited by: Hall R, Holloway JD. Leiden: Backhuys Publishers; 1998:2 I I-234.

48. Harmon LI, Schulte JA, Larson A, Losos JB: Tempo and mode of evolutionary radiation in iguanian lizards. Science 2003, 301:96I-964.

49. Johnson KR, Ellis B: A tropical rainforest in Colorado $\mathbf{1 . 4}$ million years after the Cretaceous-Tertiary boundary. Science 2002, 296:2379-2383

50. Wilf $P$, Johnson KR: Land plant extinction at the end of the Cretaceous: a quantitative analysis of the North Dakota megafloral record. Paleobiology 2004, 30:347-368.

5I. Tiffney BH: Perspectives on the origin of the floristic similarity between eastern Asia and eastern North America. J Arnold Arb 1985, 66:73-94.

52. Zachos J, Pagani M, Sloan L, Thomas E, Billups K: Trends, rhythms, and aberrations in global climate $65 \mathrm{Ma}$ to present. Science 200I, 292:686-693.

53. Wilf P: Late Paleocene-early Eocene climate changes in southwestern Wyoming: Paleobotanical analysis. Geol Soc Am Bull 2000, I I 2:292-307.

54. Wilf P, Rubén Cuneo N, Johnson KR, Hicks JF, Wing SL, Obradovich JD: High plant diversity in Eocene South America: evidence from Patagonia. Science 2003, 300: I22-125.
55. Wolfe JA: Some aspects of plant geography of the northern hemisphere during the Late Cretaceous and Tertiary. Ann Miss Bot Gard 1975, 62:264-279.

56. dePamphilis CW, Palmer JD: Loss of photosynthetic and chlororespiratory genes from the plastid genome of a parasitic flowering plant. Nature 1990, 348:337-339.

57. Bungard RA: Photosynthetic evolution in parasitic plants: insights from the chloroplast genome. BioEssays 2004, 26:235-247.

58. Jaramillo CA: Response of tropical vegetation to Paleogene warming. Paleobiology 2002, 28:222-243.

59. Maas PJM, Maas-van de Kamer H, van Benthem J, Snelders HCM, Rübsamen T: Burmanniaceae. Flora Neotropica 1986, 42: I- I89.

60. Maas-van de Kamer $\mathrm{H}$ : Burmanniaceae. In Families and genera of vascular plants, Monocotyledons, Lilianae (except Orchidaceae) Edited by: Kubitzki K. Berlin: Springer; 1998:154-164.

6I. Merckx V, Schols P, Maas-Van de Kamer H, Maas P, Huysmans S, Smets E: Phylogeny and evolution of Burmanniaceae (Dioscoreales) based on nuclear and mitochondrial data. Am J Bot 2006, 93: 1684-1698.

62. White TJ, Burns T, Lee S, Taylor J: Amplification and direct sequencing of fungal ribosomal RNA genes for phylogenetics. In PCR protocols: a guide to methods and applications Edited by: Innis M, Gelfand D, Sininsky J, White T. San Diego: Academic Press; 1990:315-322.

63. Staden R, Beal K, Bonfield J: The Staden Package. In Computer Methods in Molecular Biology Edited by: Miseners S, Krawetz S. New York: Humana Press; 1998: I I5-130.

64. Maddison DR, Maddison WP: MacClade 4: analysis of phylogeny and character evolution, Version 4.0I Sunderland: Sinauer Associates; $200 \mathrm{I}$.

65. Simmons MP, Ochoterena $\mathrm{H}$ : Gaps as characters in sequencebased phylogenetic analyses. Syst Biol 2000, 49:369-38I.

66. Müller K: SeqState - Primer design and sequence statistics for phylogenetic DNA data sets. Appl Bioin 2005, 4:65-69.

67. Swofford DL: PAUP*. Phylogenetic analysis using parsimony (* and other methods), Version 4 Sunderland: Sinauer Associates; 2002.

68. Posada D, Crandall KA: MODELTEST: testing the model of DNA substitution. Bioinformatics 1998, 14:817-818.

69. Ronquist F, Huelsenbeck JP, Mark $P$ van der: MrBayes 3.I Manual. Draft 5/I7/2005. [http://mrbayes.csit.fsu.edu/mb3.I manual.pdf].

70. Huelsenbeck JP, Ronquist F: MRBAYES. Bayesian inference of phylogeny. Bioinformatics 200I, I7:754-755.

7I. Ronquist F, Huelsenbeck JP: MRBAYES 3: Bayesian phylogenetic inference under mixed models. Bioinformatics 2003, 19:1572-1574.

72. Rambaut A, Drummond AJ: Tracer
vl.4 2007 [http:/l beast.bio.ed.ac.uk/tracer]

73. Magallón S, Sanderson MJ: Absolute diversification rates in angiosperm clades. Evolution 200I, 55: 1762-1780.

74. Chase MW: Monocot relationships: an overview. Am J Bot 2004, 91:1645-1655.

75. Sanderson MJ: Estimating absolute rates of molecular evolution and divergence times: a penalized likelihood approach. Mol Biol Evol 2002, 19:101-109.

76. Gandolfo MA, Nixon KC, Crepet WL: Triuridaceae fossil flowers from the Upper Cretaceous of New Jersey. Am J Bot 2002, 89:1940-1957.

77. Rudall P, Bateman RM: Morphological phylogenetic analysis of Pandanales: testing constrasting hypotheses of floral evolution. Syst Bot 2006, 31:223-238.

78. Rodriguez-de la Rosa RA, Cevallos-Ferriz SRS: Upper Cretaceous Zingiberalean fruits with in situ seeds from southeastern Coahuila, Mexico. Int J Plant Sci 1994, I 55:786-805.

79. Bremer K: Early Cretaceous lineages of monocot flowering plants. Proc Natl Acad Sci USA 2000, 97:4707-47I I.

80. Harley MM: Palm pollen and the fossil record. In PhD thesis University of East London and Royal Botanic Garden, Kew; 1996.

8I. Linder HP: The evolutionary history of the Poales/Restionales: a hypothesis. Kew Bull 1987, 42:297-3I8.

82. Ramírez SR, Gravendeel B, Singer RB, Marshall CR, Pierce NE: Dating the origin of the Orchidaceae from a fossil orchid with its pollinator. Nature 2007, 448: 1042-1045.

83. Wikström N, Savolainen V, Chase MW: Evolution of the angiosperms: calibrating the family tree. Proc $R$ Soc $B 2001$, 268:22II-2220. 
84. Davies TJ, Barraclough TG, Chase MW, Soltis PS, Soltis DE, Savolainen V: Darwin's abominable mystery: Insights from a supertree of the angiosperms. Proc Natl Acad Sci USA 2004, I0I: 1904-1909.

85. Leebens-Mack J, Raubeson LA, Cui L, Kuehl JV, Fourcade MH, Chumley TW, Boore JL, Jansen RK, dePamphilis CW: Identifying the basal angiosperm node in chloroplast genome phylogenies: sampling one's way out of the Felsenstein zone. Mol Biol Evol 2005, 22: $1948-1963$.

86. Sanderson MJ: r8s: inferring absolute rates of molecular evolution and divergence times in the absence of a molecular clock. Bioinformatics 2003, 19:301-302.

87. Drummond AJ, Rambaut A: BEAST: Bayesian evolutionary analysis by sampling trees. BMC Evol Biol 2007, 7:2। 4 .

88. BEAST partitioning [http://tlpcouvreur.googlepages.com/beast partitioning]

89. Nee S, Holmes EC, May RM, Harvey PH: Extinction rates can be estimated from molecular phylogenies. Phil Trans $R$ Soc B 1994 , 344:77-82.

90. Roelants K, Gower DJ, Wilkinson M, Loader SP, Biju SD, Guillaume K, Moriau L, Bossuyt F: Global patterns of diversification in the history of modern amphibians. Proc Natl Acad Sci USA 2007, 104:887-892.

91. Rambaut A: PhyloGen, version I.I. 2002 [http:// evolve.zoo.ox.ac.uk/software/PhyloGen].

92. Pybus OG, Rambaut A, Holmes EC, Harvey PJ: New inferences from tree shape: numbers of missing taxa and population growth rates. Syst Biol 2002, 5 I:88I-888.

93. Kozak KH, Weisrock DW, Larson A: Rapid lineage accumulation in a non-adaptive radiation: phylogenetic analysis of diversification rates in eastern North American woodland salamanders (Plethodontidae: Plethodon). Proc R Soc B 2006, 273:539-546.

94. Pybus OG, Rambaut A: GENIE: estimating demographic history from molecular phylogenies. Bioinformatics 2002, 18: 1404-| 405.

95. Rambaut A, Harvey PH, Nee S: End-Epi: an application for inferring phylogenetic and population dynamical processes from molecular sequences. CABIOS 1997, 13:303-306.

96. Rambaut A, Charleston M: TreeEdit v.I.0 alpha 10. 2002 [http:// evolve.zoo.ox.ac.uk/software/TreeEdit].

97. Paradis E: Testing for constant diversification rates using molecular phylogenies: a general approach based on statistical tests for goodness of fit. Mol Biol Evol 1998, I5:476-479.

98. McKenna DD, Farrell BD: Tropical forests are both evolutionary cradles and museums of leaf beetle diversity. Proc Natl Acad Sci USA 2006, 103:10947-1095I.

99. Paradis E, Claude J, Strimmer K: APE: Analyses of phylogenetics and evolution in $\mathbf{R}$ language. Bioinformatics 2004, 20:289-290.

100. Chan KMA, Moore BR: SymmeTREE: whole-tree analysis of differential diversification rates. Bioinformatics 2005, 21:1709-1710.

101. Ronquist F: Dispersal-vicariance analysis: new approach to the quantification of historical biogeography. Syst Biol 1997, 46:195-203.

102. Takhtajan AL: Floristic regions of the world Los Angeles: University of California Press; 1986.
Publish with Bio Med Central and every scientist can read your work free of charge

"BioMed Central will be the most significant development for disseminating the results of biomedical research in our lifetime. "

Sir Paul Nurse, Cancer Research UK

Your research papers will be:

- available free of charge to the entire biomedical community

- peer reviewed and published immediately upon acceptance

- cited in PubMed and archived on PubMed Central

- yours - you keep the copyright

Submit your manuscript here:

http://www.biomedcentral.com/info/publishing_adv.asp
BioMedcentral 